\title{
A Randomized, Double-Blind, Placebo-Controlled, Crossover Trial of Mifepristone in Gulf War Veterans with Chronic Multisymptom Illness
}

\author{
Julia A. Golier, MD ${ }^{\mathrm{a}, \mathrm{b}}$ \\ Kimberly Caramanica, $\mathrm{MPH}^{\mathrm{a}}$ \\ Andreas C. Michaelides, $\mathrm{PhD}^{\mathrm{a}}$ \\ Iouri Makotkine, $\mathrm{MD}^{\mathrm{a}, \mathrm{b}}$ \\ James Schmeidler, $\mathrm{PhD}^{\mathrm{b}}$ \\ Philip D. Harvey, $\mathrm{PhD}^{\mathrm{c}}$ \\ Rachel Yehuda, $\mathrm{PhD}^{\mathrm{a}, \mathrm{b}}$
}

a James J. Peters VA Medical Center, OOMH-526; 130 West Kingsbridge Road, Bronx, NY, 10468

${ }^{\mathrm{b}}$ Psychiatry Department, Icahn School of Medicine at Mount Sinai, 1428 Madison Ave, New York, NY 10029 New York, NY

${ }^{\mathrm{c}}$ Miller School of Medicine, University of Miami, 1600 NW 10th Ave \#1140, Miami, FL 33136

Corresponding Author: Julia Golier, MD; James J. Peters VA Medical Center, OOMH-526; 130 West

Kingsbridge Road, Bronx, NY, 10468; Tel: (718) 584-9000 ext. 5196; Fax: (718) 741-4775, julia.golier@va.gov

Keywords: Gulf War; mifepristone; cmi; dexamethasone; acth; cortisol; verbal learning 


\section{Abstract}

No pharmacological treatments have been demonstrated to effectively treat chronic multisymptom illness (CMI) in Gulf War veterans (GWV). This study assessed the effect of the glucocorticoid receptor antagonist mifepristone in GWV with CMI. A randomized, double-blind, cross-over trial of mifepristone, with two six-week treatment phases separated by a one-month washout period, was conducted at a Veterans Affairs (VA) hospital between 2008 and 2011. Participants were randomized to receive either $200 \mathrm{mg}$ of mifepristone per day or matched placebo first. The primary clinical outcome measure was change in self-reported physical health. Neurocognitive functioning and self-reported measures of depression, PTSD, and fatigue were secondary outcomes. Sixty-five participants enrolled, of whom 36 were randomized and 32 (mean age, 49.1 (7.2) years) completed the study. Physical and mental health status and neurocognitive functioning were poor at baseline. Mifepristone treatment was not associated with improvement in self-reported physical health $(\mathrm{p}=0.838)$ or in other self-reported measures of mental health. Mifepristone treatment was significantly associated with improvements in verbal learning $(\mathrm{p}=0.008, \mathrm{~d}=0.508)$, in the absence of improvement in other cognitive measures (working memory $(\mathrm{p}=0.914)$, visual learning $(\mathrm{p}=0.643)$ and a global composite measure $(\mathrm{p}=0.937)$. Baseline morning cortisol levels and lysozyme $\mathrm{IC}_{50-\mathrm{DEX}}$, a measure of peripheral glucocorticoid sensitivity, displayed a significant relationship with endpoint verbal learning scores ( $\mathrm{p}=0.012$ and $\mathrm{p}=0.007$, respectively). The magnitude of cortisol change during treatment mediated the improvement in verbal learning.

This study was negative for the primary and secondary clinical outcomes. However, the data suggest a moderate dose of mifepristone may have circumscribed cognitive-enhancing effects in CMI. Further study is warranted to determine whether and through which mechanisms mifepristone treatment can yield clinically meaningful improvement in cognitive function in CMI or other neuropsychiatric conditions associated with HPA axis dysregulation. 


\subsection{Introduction}

Despite advances in the assessment and understanding of chronic multi-symptom illness (CMI) in Gulf War veterans (GWV), no pharmacological treatments have been demonstrated to effectively treat this medically unexplained illness. Novel treatment approaches are needed to improve the health of the 34-65\% of GWV who experience CMI (Fukuda et al., 1998; Steele, 2000; Blanchard et al., 2006). Dysregulation of the hypothalamic-pituitary-adrenal (HPA) axis is a potential treatment target for CMI in GWV (Golier et al., 2006a; Golier et al., 2007; Broderick et al., 2013) since GWV have been shown to have greater responsivity to glucocorticoids than non-deployed veterans, as evidenced by greater dexamethasone (DEX) induced suppression of ACTH and cortisol (Golier et al., 2006 a,b). GWV also show substantial reductions in both basal and metyrapone-stimulated levels of ACTH compared to healthy non-deployed veterans (Golier et al., 2007; Golier et al., 2009). The mechanisms responsible for this apparent reduced drive to the HPA axis in the face of excess responsivity to neuroendocrine challenge have yet to be definitively characterized. However, their possible pathophysiological relevance is supported by their associations with health symptoms and specific deployment-related environmental exposures (e.g. pyridostigmine bromide)which have been consistently linked to Gulf War illness in epidemiological studies.

To the extent that enhanced glucocorticoid receptor sensitivity is a molecular driver of CMI, reducing GR sensitivity or blocking GR activity may be therapeutic. Accordingly, we examined the clinical effect of mifepristone, a selective type II glucocorticoid receptor antagonist, in GWV with CMI. Mifepristone binds to the same site as the synthetic glucocorticoid dexamethasone and blocks the negative feedback control of cortisol on the pituitary (Gaillard and Riondel, 1984). Given that glucocorticoids influence cognitive performance, a glucocorticoid-based treatment may also be warranted to address the neurocognitive symptoms and concomitant deficits in attention, executive functioning, and verbal learning and memory (Blanchard et al., 2006; Vasterling et al., 1998; Binder et al., 1999; Lange et al., 2001; Axelrod and Milner, 1997; White et al., 2001; Vythilingam and Luckenbaugh, 2005) observed in Gulf War veterans. Mifepristone has been shown to have beneficial effects on mood and/or cognition in 
other neuropsychiatric disorders including psychotic depression and Alzheimer's disease (Belanoff et al., 2001; Chu and Matthias, 2001; Pomara et al., 2002, Young et al., 2004; Simpson et al., 2005; Flores et al., 2006, Watson et al., 2012). Accordingly, we hypothesized that mifepristone would improve physical and mental health symptoms and cognitive functioning in GWV with CMI. A moderate dose strategy (200 mg/day x 6 weeks) was used to minimize side effects and allow for longer-term treatment than a highdose strategy would permit. This dosing strategy followed the regimen outlined for the study of Alzheimer's disease (Pomara et al., 2002, Belanoff et al., 2002a). HPA axis biomarkers were also obtained before and during treatment to determine predictors of response and mechanisms of action.

\subsection{Materials and Methods}

This was a randomized, placebo-controlled, crossover trial that took place at a Veterans Affairs (VA) hospital between 2008 and 2011. Participants, research coordinators, and assessors were blind to treatment condition. GWV outpatients who met the Kansas case definition of CMI (qualifying symptoms in three of six symptom domains: fatigue, pain, neuro-cognitive-mood, dermatologic, gastrointestinal, and respiratory) (Steele, 2000) were eligible. A GWV was defined as a veteran who was deployed by the U.S. military to the Persian Gulf between August 1, 1990 and December 30, 1991. Participants with a major medical or neurological disorder or traumatic brain injury, which could explain their health symptoms, were ineligible. GWV with a lifetime diagnosis of schizophrenia, schizoaffective disorder, or bipolar disorder, current suicidal ideation, psychiatric hospitalization or attempted suicide within the previous two years, a known allergy to mifepristone, current oral corticosteroids usage, or an unwillingness to use effective forms of contraception during the study were also excluded. Participants receiving psychiatric medications were eligible to participate if they had been stabilized at a therapeutic dose for a minimum of four weeks prior to randomization. The protocol was approved by the Institutional Review Board of the James J. Peters VA Medical Center. Written informed consent and HIPAA authorization were obtained from all participants prior to the initiation of any study procedures. No changes were made to the trial design once it began. 
For assessment of biomarkers, fasting blood was obtained between $0800 \mathrm{~h}-0830 \mathrm{~h}$ on two consecutive mornings. Participants ingested $0.5 \mathrm{mg}$ of DEX at $2300 \mathrm{~h}$ at home before the second blood draw. Plasma cortisol levels were determined using a commercially available radioimmunoassay (RIA) kit (DiaSorin Inc. Stillwater, Minnesota). ACTH levels were determined on hourly samples using an immunoradiometric assay kit from Nichols Institute Diagnostics (San Juan Capistrano, California) based on the binding of antibodies with high affinity and specificity for defined amino acid regions of the ACTH molecule.

The lysozyme IC-50 test was calculated from the day 1 blood sample as the concentration of DEX required to inhibit lysozyme activity by $50 \%$ (Panarelli et al., 1994). Cells $\left(3.5-4.0 \times 10^{5}\right)$ were incubated with multiple concentrations of DEX from 0 to $200 \mathrm{nM}$ at $37^{\circ} \mathrm{C}$ in a humidified atmosphere with $5 \% \mathrm{CO}_{2}$ for three days. Each concentration of DEX was incubated in triplicate. After centrifugation, supernatant was removed and samples were stored at $-70{ }^{\circ} \mathrm{C}$ until analysis. The supernatant $(50 \mu \mathrm{l})$ was incubated with $150 \mu$ of substrate in 96 well plates at $37^{\circ} \mathrm{C}$ for 30 min with shaking. The density was read at 450 $\mathrm{nm}$ on microplate spectrophotometer. Samples were run in triplicate and the results were expressed as the average. The standard was pure lysozyme from chicken egg white (Sigma Chemical Co.) dissolved in RPMI-1640 as the same as used for cell culture. The inhibition curve was drawn as concentration of DEX vs. relative activity of lysozyme. The results were expressed as $\mathrm{IC}_{50} \mathrm{DEX}[\mathrm{nM}]$ based on the concentration of DEX at which 50\% of lysozyme activity was inhibited. The intra- and inter-assay coefficients of variation were 6.9 and $9.8 \%$ respectively.

Morning plasma cortisol and ACTH levels were measured to assess the magnitude of mifepristone's neuroendocrine effects. The lysozyme $\mathrm{IC}_{50 \text {-DEX }}$ was used as a measure of mifepristone's antagonism of peripheral GR sensitivity longitudinally. The change in cortisol and ACTH in response to low-dose DEX was used as a measure of GR responsivity at baseline. 


\subsection{Participants}

Of the $65 \mathrm{GWV}$ enrolled into the study, 13 were lost to follow-up prior to the initial evaluation, nine were medically ineligible, five did not meet CMI criteria, and two withdrew consent. 36 eligible GWV were randomized to receive either $200 \mathrm{mg}$ of mifepristone or matched placebo first; one did not initiate treatment, one withdrew in treatment phase I due to the time commitment, one was terminated from the study during treatment phase I due to elevated blood glucose, and one was lost to follow-up after the treatment phase II baseline visit. The final study sample consisted of 32 GWV with CMI (see figure 1).

\subsection{Randomization}

Participants were enrolled by a research coordinator. Randomization was performed by the pharmacy using a computer generated randomization list, which assigned an equal number of participants to mifepristone and placebo first. Identically matched drug and placebo pills were obtained from Danco Laboratories, LLC. The medication was electronically ordered and only the pharmacist knew whether mifepristone was being dispensed first or second.

\subsection{Procedure}

The diagnostic assessment included a complete medical evaluation, the Clinician Administered PTSD Scale (CAPS), and the Structured Clinical Interview for DSM-IV (SCID). Self-report questionnaires were administered to assess CMI case status (Kansas Gulf War Questionnaire), physical and mental health (SF36), combat exposure severity and characteristics of deployment (Combat Exposure Questionnaire [CEQ]), childhood trauma (Childhood Trauma Questionnaire [CTQ]), cognitive impairment (Cognitive Failures Questionnaire [CFQ]), fatigue (Multidimensional Fatigue Inventory [MFI-20]), and symptoms of depression (Beck Depression Inventory [BDI]) and posttraumatic stress (PTSD Checklist [PCL]). 
The Kansas Gulf War Questionnaire is a self-report measure used to identify symptoms in veterans across six symptom domains: fatigue, pain, neurological-cognitive, skin, gastrointestinal, and respiratory. Veterans meet criteria if they have qualifying symptoms in three of the six domains and no excluding medical diagnoses. This definition is currently the state-of-the art approach with regard to assessing CMI.

All participants underwent a medical assessment by a single physician rater which included review of symptoms, vital sign assessment, routine laboratory assessment, review of concomitant medication, physical examination, complete medical history and an EKG. A diagnosis of CMI was not made if the participant had significant comorbid medical syndromes which might explain their symptoms or increase their risk of adverse events. Exclusions included cancer, diabetes, chronic infectious disease, liver disease, TBI or another major medical or neurologic condition likely to contribute to their symptom profile.

During both treatment phases, which were separated by a one month wash-out period, participants were evaluated in-person every two weeks (baseline, week two, week four, and endpoint) after which participants completed a one month follow-up visit. Clinical and neuroendocrine test batteries were measured at baseline, week two, and endpoint for each treatment phase and at one month follow-up. Selfreport questionnaires, vital signs, adverse events, and concomitant medications were obtained at every visit.

No stopping rules were determined a priori. An independent data monitoring committee reviewed efficacy and safety data annually and deemed the study safe at each evaluation.

\subsection{Measures}

The primary clinical outcome measure was the change in the physical health components score (PCS) derived from the acute form of the veterans SF-36 health survey. A secondary clinical outcome measure was the change in the mental health components score (MCS) of the SF-36. Additional secondary clinical 
outcome measures included self-reported symptoms of fatigue, depression, and PTSD as measured by the MFI-20, BDI, and PCL, respectively.

The neurocognitive outcome measures were baseline to endpoint changes in spatial working memory, verbal learning, and visual learning as measured by the Wechsler Memory Scale-III Spatial Span and Letter-Number Span, the Hopkins Verbal Learning Test, and the Brief Visuospatial Memory TestRevised, respectively, using normative standards from the MATRICS Consensus Cognitive Battery. The normative composite score from this test battery was used, which is an equally weighted average of standard performance scores across all of the subtests. The MATRICS was normed on a community sample of healthy individuals who were selected for diversity in age, sex, and educational attainment $(n=300)($ Kern et al., 2008).

\subsection{Analyses}

Data are presented for 32 completers, defined as completing at least two weeks of treatment in both phases. For measures of physical and mental health, the last observation was carried forward for patients who did not complete the study, whether due to withdrawal, missed visits, or the development of side effects. Primary and secondary outcome measure change scores were calculated as the difference between the change from baseline to endpoint in each drug phase, and then calculated as mifepristone change minus placebo change. For each measure, treatment order effects were assessed using independent sample t-tests; if order effects were not present, a simple sample t-test was used on each outcome measure change score. Treatment phases were then separated, resulting in most participants contributing two observations, and a hierarchical regression was performed to evaluate whether neuroendocrine changes (cortisol, ACTH, glucocorticoid sensitivity) predict outcome. Cortisol and ACTH variables were created by subtracting 8am cortisol levels (pre-dexamethasone) on Day 1 from Day 2 (post-dexamethasone) to obtain the magnitude of suppression to DEX. This variable was tested as a mediator of significant outcomes using regression analyses, as previously described. Full mediation was ascertained if significant 
relationships between drug condition and cortisol change and cortisol change and outcome were present, as well as, a non-significant association between drug condition and outcome. Years of education was added to each regression to control for group differences and baseline cortisol levels were added to the model predicting verbal learning in order to control for individual differences. All tests of significance were two-sided with statistical significance set at $p<0.05$. No outcome measure changes were made once the study started.

\subsection{Power analyses}

The intended sample size of 40 was not reached due to recruitment difficulties. Based on a sample size of 32, the adjusted power was determined to be above 0.995 and 0.78 for the single sample t-test with large and medium effect sizes, respectively.

\subsection{Results}

Data on sociodemographic characteristics and self-reported physical and mental health measures are shown in Tables 1 and 2, respectively. The mean age was 49.1 (7.2) years and the exclusively male sample was ethnically diverse. The mean level of education was 13.3 (1.8) years, with most participants $(43.8 \%)$ having some college or vocational school education. The majority of GWV were employed full time $(56.3 \%)$ and were married or had a common law marriage (53.1\%). No significant group differences in baseline self-reported variables were observed. Based on the CAPS, 59.4\% $(n=19)$ also met criteria for PTSD, 21.9\% $(n=7)$ met criteria for current Major Depressive Disorder, 6.3\% $(n=2)$ met criteria for dysthymia and $3.1 \%$ for panic disorder $(n=1)$. The CTQ results suggest that as a group the sample did not have extensive exposure to adverse early life experiences.

Participants endorsed a mean of 4.9 (1.2) out of six Gulf War symptom domains. For the SF-36, mean 
PCS and MCS scores were 33.6 (10.0) and 29.9 (12.2), respectively, reflecting relatively poor healthrelated quality of life. These scores were significantly lower than the US population norms for individuals 45-54 years old $(\mathrm{PCS}=49.62, \mathrm{MCS}=50.54)($ Kazis, 2000) and the VA national average $(\mathrm{PCS}=35.2$, MCS=43.6) (Ware, 1998). The mean PCL score was 55.8 (19.4) and the mean BDI score was 25.2 (11.0) indicating the presence of associated symptoms of posttraumatic stress and depression. The mean CEQ score (50.1 (9.6)) indicated moderate exposure to combat stress. There were no significant differences between groups for any of the sociodemographic variables.

The normed cognitive baseline data is useful to characterize the cognitive status of these veterans, which was well below average at baseline. More specifically, working memory and overall composite scores were greater than one standard deviation below the mean (37.84 (12.45) and 35.75 (12.90), respectively). Verbal learning was one standard deviation (40.60 (9.76)) and visual learning (45.53 (10.71)) was half a standard deviation lower than the normative scores previously obtained.

Change scores from baseline to endpoint for all outcome measures and neuroendocrine variables are shown in Table 2 by treatment assignment (mifepristone vs. placebo first) and treatment phase. Neurocognitive, clinical, and neuroendocrine outcomes, calculated as drug change minus placebo change are shown in Table 3.

Mifepristone treatment was not associated with improvement in the primary outcome of self-reported physical health status $(\mathrm{p}=0.838)$ or the secondary outcome of self-reported mental health status $(\mathrm{p}=0.423)$, as measured by the SF-36. Nor was it associated with changes in PTSD symptom severity $(\mathrm{p}=0.130)$ and depression severity $(\mathrm{p}=0.595)$.

Chronic administration of moderate-dose mifepristone did result in significant improvement in verbal learning $(\mathrm{p}=0.008, \mathrm{~d}=0.508)$; groups displayed a mean difference of 5.225 (95\% CI, $1.450-9.002)$. As 
shown in Figure 2, verbal learning change scores increased from baseline to endpoint in both treatment phases among those taking mifepristone, while mean scores decreased from baseline to endpoint for those on placebo. Mifepristone treatment was not associated with improvements in working memory $(\mathrm{p}=0.914)$ or visual learning $(\mathrm{p}=0.643$ ) or on the overall composite score $(\mathrm{p}=0.937)$. The finding for verbal learning remains significant after controlling for multiple cognitive outcome measures (four).

Treatment with mifepristone was associated with increased levels of cortisol and ACTH typical of GR antagonists. Mifepristone treatment was associated with a 113\% increase in plasma cortisol level and a $510 \%$ increase in ACTH level, both of which were significant $(\mathrm{p}<0.001)$. With the removal of one outlier, the mean increase in ACTH with active treatment was 158\%. Non-significant increases were observed for lysozyme $\mathrm{IC}_{50-\mathrm{DEX}}$ levels $(\mathrm{p}=0.138)$. Treatment order effects were not significant for primary or secondary outcome measures. Study cortisol fluctuations are depicted in Figure 3. One participant in the mifepristone treatment group developed a rash assessed at week two and was taken off the study drug. The rash fully resolved.

The hierarchical regression examining the relationship between HPA axis biomarkers and verbal learning is shown in Table 4. The first step examines the relationship between treatment phase and drug group on verbal learning $\mathrm{F}(4,51)=3.282$, $\mathrm{p}=0.018$, and accounts for $21 \%$ of endpoint verbal learning scores. Without the other variables taken into account, treatment order significantly predicted verbal learning $(\beta=-2.739, p=0.028)$. Baseline verbal learning score was entered into the next block and this overall model was significant, $\mathrm{F}(5,50)=11.412$, $\mathrm{p}<0.001$, accounting for $53 \%$ of endpoint verbal learning scores. As expected, drug group significantly predicted outcome $(\beta=2.515, \mathrm{p}=0.009)$. The final step, which included HPA axis biomarkers, was also significant, $F(8,47)=10.687$, $p<0.001$ and accounted for $65 \%$ of verbal learning. In addition to drug group $(\beta=2.464, \mathrm{p}=0.005)$, morning cortisol difference and lysozyme $\mathrm{IC}_{50}$ were both significant unique predictors of endpoint verbal learning scores $(\beta=0.475, \mathrm{p}=0.012$ and $\beta=-$ $1.115, \mathrm{p}=0.007$, respectively) with lysozyme $\mathrm{IC}_{50-\mathrm{DEX}}$ displaying an inverse relationship. It should be noted 
that treatment order was not a significant predictor in the last steps of the analysis.

The results of the mediation analysis are depicted in Table 5. The first overall model (path a) was significant, $F(5,56)=7.743, \mathrm{p}<0.001$ and account for $41 \%$ of cortisol changes. Drug condition was a significant unique predictor of cortisol change $(\beta=4.40, \mathrm{p}<0.001)$. Thus, for participants who were prescribed mifepristone, an almost $4.5 \mathrm{mcg}$ cortisol difference was observed. The next model (path c) was also significant $\mathrm{F}(5,58)=13.282$, $\mathrm{p}<0.001$ and accounted for $53 \%$ of endpoint verbal learning scores. Drug condition was a significant unique predictor $(\beta=2.139, \mathrm{p}=0.012)$ of verbal learning. Full mediation was shown in the final regression (path $\mathrm{b}$ and $\mathrm{c}$ ), $\mathrm{F}(7,54)=11.698, \mathrm{p}<0.001$, where it accounted for $60 \%$ of verbal learning scores, and drug condition was no longer a significant unique predictor of verbal learning $(\beta=1.014, \mathrm{p}=0.301)$, but cortisol change was $(\beta=0.310, \mathrm{p}=0.016)$. The indirect effect of drug condition on verbal learning scores is 1.365 . Therefore, a 1.4 verbal learning score increase was observed through the effect of drug condition on cortisol difference for participants prescribed mifepristone even when controlling for baseline cortisol levels. A graphical depiction of the mediating effects of cortisol is shown in Figure 4.

\subsection{Discussion}

Chronic administration of a moderate-dose of the glucocorticoid receptor antagonist mifepristone in GWV with CMI resulted in the anticipated neuroendocrine changes (increased plasma cortisol and ACTH levels) but was not associated with improvement in the primary outcome measure of self-reported physical health status or the secondary outcome measures of self-reported mental health status, depression, fatigue and post-traumatic stress symptoms.

Treatment with mifepristone did, however, selectively improve verbal learning, which was among the cognitive domains impaired in the current sample at pre-treatment. Although there are few studies of the neuropsychological effects of mifepristone, improvement has been reported using a variety of doses and regimens. For example, a single $200 \mathrm{mg}$ dose enhanced memory retrieval in healthy men (Rimmele et al., 
2013). In patients with bipolar disorder, one week of treatment with $600 \mathrm{mg} /$ day improved spatial working memory (Young et al., 2004 and Watson et al., 2012). Enhancements in verbal learning and executive function were reported following chronic treatment ( $300 \mathrm{mg} /$ day for 12 weeks) in older adults with anxiety disorder and neuroendocrine impairment (Lenze et al., 2014). In each of these studies, the positive effects were confined to circumscribed areas of cognition, primarily memory performance, rather than appearing as a global effect on all aspects of cognition studied.

In the current study, the treatment-related improvements in verbal learning suggest the possibility of hippocampal involvement (Milner, 1965; Smith \& Milner, 1981; Maki, 2009). Alterations reflecting hippocampal dysfunction have previously found to be associated with GWV CMI in neuroimaging studies (Menon et al., 2004; Li et al., 2011, Chao et al, 2010, Li et. al, 2011; Yehuda et al., 2010). Animal models of Gulf War illness, in which rodents are exposed to stress and specific neurotoxins implicated in the disorder (e.g., pyridostigmine bromide, DEET, and permethrin), have confirmed reduced neurogenesis, partial neuron loss and mild inflammation in the hippocampus (Parihar et al., 2013; AbdelRahman et al., 2002, Li et al., 2011). Moreover, stressed or cognitively-impaired rodents demonstrated improved performance on hippocampal-dependent learning following exposure to mifepristone (Oitzl et al., 1998; Aisa et al., 2007; Zuo et al., 2011), likely resulting from reversal of corticosterone-induced reductions in hippocampal neurogenesis (Oomen et al., 2007; Mayer et al., 2006). It is therefore possible that mifepristone yields a similar neuroprotective effect on hippocampal function in Gulf War CMI, contributing to the observed finding.

The exact mechanism through which mifepristone acted to alter memory performance in this study cannot be known due to limitations of the current design, but it is possible to generate explanations based on knowledge of mifepristone actions on glucocorticoids, as well as the complex effects of glucocorticoids on cognition. Mifepristone blocks central glucocorticoid receptors and the efflux of cortisol from the brain, which is hypothesized to recalibrate the HPA axis through an up-regulation of mineralocorticoid receptors and down-regulation of glucocorticoid receptors (Belanoff et al., 2002b). Therefore, the 
enhanced glucocorticoid responsivity observed in symptomatic GWV (Golier et al., 2007) might have been attenuated by mifepristone through blockade of central glucocorticoid receptors. Several observations support the view that mifepristone's effects may have resulted from its actions on and through a disrupted HPA axis system. There was an exaggerated response to glucocorticoids at pretreatment, reflected by an enhanced cortisol suppression following the low-dose dexamethasone suppression test (mean level $85.17 \%$ is higher than what has been observed in healthy non-deployed veterans (Gaillard and Riondel, 1984)), and similar to that previously observed (Golier et al., 2006 a,b). Additionally, the verbal learning improvement was mediated by the magnitude of neuroendocrine response, and the lower baseline cortisol level and enhanced peripheral glucocorticoid sensitivity (as measured by the lysozyme $\left.\mathrm{IC}_{50-\mathrm{DEX}}\right)$ were associated with improved cognitive outcomes. While correlative, that pre-treatment neuroendocrine status is a relevant predictor of mifepristone's effects on verbal memory offers the possibility that individualized treatment approaches utilizing glucocorticoid receptor antagonists could be realized in the future.

The controlled nature of this study allows us to generalize findings to other GWV with CMI. Using a crossover design allowed us to utilize each participant group as their own control. This study had a low attrition rate, providing us with a good data set. While this is a strong benefit, some disadvantages must be considered. For example, each neuropsychological measure was administered multiple times. Alternate forms were utilized to assess three of the domains studied in order to prevent practice effects, including verbal learning. However, it is not known whether these multiple administrations affected the ability to detect changes in cognition.

Future studies are needed to further explore neuroendocrine approaches to treating CMI with a focus on cognitive outcomes. These may include using a broader range of doses of mifepristone, administering it over a longer period of time, or exploring other glucocorticoid receptor antagonists. The potentially beneficial properties of mifepristone or other glucocorticoid receptor antagonists and their mechanisms of 
action should be explored for the treatment of neuropsychiatric impairments in CMI and overlapping conditions associated with HPA axis dysregulation.

\subsection{Acknowledgements and Disclosures}

This study is registered with ClinicalTrials.gov (NCT00691067) and was solely funded by the Department of Defense (DoD). The DoD did not influence any aspects of the study design or manuscript preparation. The authors declare no conflicts of interests. The authors also acknowledge the assistance of Ahmed El-Razi, B.A. in the revising the manuscript. 


\subsection{References}

Abdel-Rahman, A., Shetty, A., Abou-Donia, M., 2002. Acute exposure to sarin increases blood brain barrier permeability and induces neuropathological changes in the rat brain: dose-response relationships. Neuroscience 113, 721-741.

Aisa, B., Tordera, R., Lasheras, B., Del Río, J., Ramírez, M.J., 2007. Cognitive impairment associated to HPA axis hyperactivity after maternal separation in rats. Psychoneuroendocrinology 32, 256-266.

Axelrod, B.N., Milner, I.B., 1997. Neuropsychological findings in a sample of Operation Desert Storm veterans. The Journal of neuropsychiatry and clinical neurosciences.

Belanoff, J.K., Flores, B.H., Kalezhan, M., Sund, B., Schatzberg, A.F., 2001. Rapid reversal of psychotic depression using mifepristone. J Clin Psychopharmacol 21, 516-521.

Belanoff, J.K., Jurik, J., Schatzberg, L.D., DeBattista, C., Schatzberg, A.F., 2002a. Slowing the progression of cognitive decline in Alzheimer's disease using mifepristone. J Mol Neurosci 19, 201 206.

Belanoff, J.K., Rothschild, A.J., Cassidy, F., DeBattista, C., Baulieu, E.-E., Schold, C., Schatzberg, A.F., 2002b. An open label trial of C-1073 (mifepristone) for psychotic major depression*. Biol Psychiatry 52, 386-392.

Binder, L.M., Storzbach, D., Anger, W.K., Campbell, K.A., Rohlman, D.S., Center, H.R., 1999. Subjective cognitive complaints, affective distress, and objective cognitive performance in Persian Gulf War veterans. Arch Clin Neuropsychol 14, 531-536.

Blanchard, M.S., Eisen, S.A., Alpern, R., Karlinsky, J., Toomey, R., Reda, D.J., Murphy, F.M., Jackson, L.W., Kang, H.K., 2006. Chronic multisymptom illness complex in Gulf War I veterans 10 years later. Am J Epidemiol 163, 66-75.

Broderick, G., Ben-Hamo, R., Vashishtha, S., Efroni, S., Nathanson, L., Barnes, Z., Fletcher, M.A., Klimas, N., 2013. Altered immune pathway activity under exercise challenge in Gulf War Illness: an exploratory analysis. Brain Behav Immun 28, 159-169.

Chao, L.L., Rothlind, J.C., Cardenas, V.A., Meyerhoff, D.J., Weiner, M.W., 2010. Effects of low-level exposure to sarin and cyclosarin during the 1991 Gulf War on brain function and brain structure in US veterans. Neurotoxicology 31, 493-501.

Chu, J.W., Matthias, D.F., Belanoff, J., Schatzberg, A., Hoffman, A.R., Feldman, D., 2001. Successful long-term treatment of refractory Cushing's disease with high-dose mifepristone (RU 486). The Journal of Clinical Endocrinology \& Metabolism 86, 3568-3573.

Flores, B.H., Kenna, H., Keller, J., Solvason, H.B., Schatzberg, A.F., 2006. Clinical and biological effects of mifepristone treatment for psychotic depression. Neuropsychopharmacology 31, 628-636.

Fukuda, K., Nisenbaum, R., Stewart, G., Thompson, W.W., Robin, L., Washko, R.M., Noah, D.L., Barrett, D.H., Randall, B., Herwaldt, B.L., 1998. Chronic multisymptom illness affecting Air Force veterans of the Gulf War. JAMA 280, 981-988. 
Gaillard, R., Riondel, A., Muller, A., Herrmann, W., Baulieu, E., 1984. RU 486: a steroid with antiglucocorticosteroid activity that only disinhibits the human pituitary-adrenal system at a specific time of day. Proceedings of the National Academy of Sciences 81, 3879-3882.

Golier, J.A., Legge, J., Yehuda, R., 2006a. The ACTH response to dexamethasone in Persian Gulf War veterans. Ann N Y Acad Sci 1071, 448-453.

Golier, J.A., Schmeidler, J., Legge, J., Yehuda, R., 2006b. Enhanced cortisol suppression to dexamethasone associated with Gulf War deployment. Psychoneuroendocrinology 31, 1181-1189.

Golier, J.A., Schmeidler, J., Legge, J., Yehuda, R., 2007. Twenty-four hour plasma cortisol and adrenocorticotropic hormone in Gulf War veterans: relationships to posttraumatic stress disorder and health symptoms. Biol Psychiatry 62, 1175-1178.

Golier, J.A., Schmeidler, J., Yehuda, R., 2009. Pituitary response to metyrapone in Gulf War veterans: relationship to deployment, PTSD and unexplained health symptoms. Psychoneuroendocrinology $34,1338-1345$.

Kazis, L.E., 2000. The veterans SF-36 health status questionnaire: development and application in the Veterans Health Administration. Medical Outcomes Trust Monitor 5, 1-2.

Kern, R.S., Nuechterlein, K.H., Green, M.F., Baade, L.E., Fenton, W.S., Gold, J.M., Keefe, R.S., Mesholam-Gately, R., Mintz, J., Seidman, L.J., 2008. The MATRICS Consensus Cognitive Battery, part 2: co-norming and standardization. Am J Psychiatry 165, 214-220.

Lange, G., Tiersky, L., DeLuca, J., Scharer, J., Policastro, T., Fiedler, N., Morgan, J., Natelson, B., 2001. Cognitive functioning in Gulf War illness. J Clin Exp Neuropsychol 23, 240-249.

Lenze, E.J., Hershey, T., Newcomer, J.W., Karp, J.F., Blumberger, D., Anger, J., Doré, P., Dixon, D., 2014. Antiglucocorticoid therapy for older adults with anxiety and co-occurring cognitive dysfunction: results from a pilot study with mifepristone. Int J Geriatr Psychiatry 29, 962-969.

Li, B., Mahan, C.M., Kang, H.K., Eisen, S.A., Engel, C.C., 2011. Longitudinal health study of US 1991 Gulf War veterans: changes in health status at 10-year follow-up. Am J Epidemiol 174, 761-768.

Maki, P., Cohen, M., Weber, K., Little, D., Fornelli, D., Rubin, L., Perschler, P., Gould, F., Martin, E., 2009. Impairments in memory and hippocampal function in HIV-positive vs HIV-negative women A preliminary study. Neurology 72, 1661-1668.

Mayer, J., Klumpers, L., Maslam, S., De Kloet, E., Joels, M., Lucassen, P., 2006. Brief treatment with the glucocorticoid receptor antagonist mifepristone normalises the corticosterone-induced reduction of adult hippocampal neurogenesis. J Neuroendocrinol 18, 629-631.

Menon, P.M., Nasrallah, H.A., Reeves, R.R., Ali, J.A., 2004. Hippocampal dysfunction in Gulf War Syndrome. A proton MR spectroscopy study. Brain Res 1009, 189-194.

Milner, B., 1965. Visually-guided maze learning in man: Effects of bilateral hippocampal, bilateral frontal, and unilateral cerebral lesions. Neuropsychologia 3, 317-338. 
Oitzl, M.S., Fluttert, M., de Kloet, E.R., 1998. Acute blockade of hippocampal glucocorticoid receptors facilitates spatial learning in rats. Brain Res 797, 159-162.

Oomen, C.A., Mayer, J.L., De Kloet, E.R., Joëls, M., Lucassen, P.J., 2007. Brief treatment with the glucocorticoid receptor antagonist mifepristone normalizes the reduction in neurogenesis after chronic stress. Eur J Neurosci 26, 3395-3401.

Panarelli, M., Holloway, C., Mulatero, P., Fraser, R., Kenyon, C., 1994. Inhibition of lysozyme synthesis by dexamethasone in human mononuclear leukocytes: an index of glucocorticoid sensitivity. The Journal of Clinical Endocrinology \& Metabolism 78, 872-877.

Parihar, V.K., Hattiangady, B., Shuai, B., Shetty, A.K., 2013. Mood and memory deficits in a model of Gulf War illness are linked with reduced neurogenesis, partial neuron loss, and mild inflammation in the hippocampus. Neuropsychopharmacology 38, 2348-2362.

Pomara, N., Doraiswamy, P.M., Tun, H., Ferris, S., 2002. Mifepristone (RU 486) for Alzheimer's disease. Neurology 58, 1436-1436.

Rimmele, U., Besedovsky, L., Lange, T., Born, J., 2013. Blocking mineralocorticoid receptors impairs, blocking glucocorticoid receptors enhances memory retrieval in humans. Neuropsychopharmacology 38, 884-894.

Simpson, G.M., El Sheshai, A., Loza, N., Kingsbury, S.J., Fayek, M., Rady, A., Fawzy, W., 2005. An 8week open-label trial of a 6-day course of mifepristone for the treatment of psychotic depression. $\mathrm{J}$ Clin Psychiatry 66, 598-602.

Smith, M.L., Milner, B., 1981. The role of the right hippocampus in the recall of spatial location. Neuropsychologia 19, 781-793.

Steele, L., 2000. Prevalence and patterns of Gulf War illness in Kansas veterans: association of symptoms with characteristics of person, place, and time of military service. Am J Epidemiol 152, 992-1002.

Vasterling, J.J., Brailey, K., Constans, J.I., Sutker, P.B., 1998. Attention and memory dysfunction in posttraumatic stress disorder. Neuropsychology 12, 125.

Vythilingam, M., Luckenbaugh, D.A., Lam, T., Morgan, C.A., Lipschitz, D., Charney, D.S., Bremner, J.D., Southwick, S.M., 2005. Smaller head of the hippocampus in Gulf War-related posttraumatic stress disorder. Psychiatry Research: Neuroimaging 139, 89-99.

Ware, J.J., 1998. U.S. Population Norms, < http://www.sf-36.org/research/sf98norms.pdf>.

Watson, S., Gallagher, P., Porter, R.J., Smith, M.S., Herron, L.J., Bulmer, S., Young, A.H., Ferrier, I.N., Group, N.-E.M.D.C.R., 2012. A randomized trial to examine the effect of mifepristone on neuropsychological performance and mood in patients with bipolar depression. Biol Psychiatry 72, 943-949.

White, R.F., Proctor, S.P., Heeren, T., Wolfe, J., Krengel, M., Vasterling, J., Lindem, K., Heaton, K.J., Sutker, P., Ozonoff, D.M., 2001. Neuropsychological function in Gulf War veterans: relationships to self-reported toxicant exposures. Am J Ind Med 40, 42-54. 
Yehuda, R., Golier, J.A., Bierer, L.M., Mikhno, A., Pratchett, L.C., Burton, C.L., Makotkine, I., Devanand, D., Pradhaban, G., Harvey, P.D., 2010. Hydrocortisone responsiveness in Gulf War veterans with PTSD: Effects on ACTH, declarative memory hippocampal [18 F] FDG uptake on PET. Psychiatry Research: Neuroimaging 184, 117-127.

Young, A.H., Gallagher, P., Watson, S., Del-Estal, D., Owen, B.M., Ferrier, I.N., 2004. Improvements in neurocognitive function and mood following adjunctive treatment with mifepristone (RU-486) in bipolar disorder. Neuropsychopharmacology.

Zuo, Z.-F., Wang, W., Niu, L., Kou, Z.-Z., Zhu, C., Zhao, X.-H., Luo, D.-S., Zhang, T., Zhang, F.-X., Liu, X.-Z., 2011. RU486 (mifepristone) ameliorates cognitive dysfunction and reverses the downregulation of astrocytic N-myc downstream-regulated gene 2 in streptozotocin-induced type-1 diabetic rats. Neuroscience 190, 156-165. 
Table 1. Sociodemographic characteristics of Gulf War veterans in overall sample

\begin{tabular}{|c|c|c|}
\hline & $\begin{array}{l}\text { Overall Sample } \\
\quad(\mathrm{n}=32)\end{array}$ & Range \\
\hline Age (years) & $49.1(7.2)$ & $39-65$ years old \\
\hline Education (years) & $13.3(1.8)$ & $11-18$ years \\
\hline \multicolumn{3}{|l|}{ Race } \\
\hline African American & $50.0 \%(\mathrm{n}=16)$ & \\
\hline Caucasian & $40.6 \%(n=13)$ & \\
\hline Other & $9.4 \%(\mathrm{n}=3)$ & \\
\hline \multicolumn{3}{|l|}{ Ethnicity } \\
\hline Hispanic & $50.0 \%(\mathrm{n}=16)$ & \\
\hline Non-Hispanic & $50.0 \%(\mathrm{n}=16)$ & \\
\hline \multicolumn{3}{|l|}{ Marital Status } \\
\hline Married/common law marriage & $53.1 \%(\mathrm{n}=17)$ & \\
\hline Single/Separated/Divorced/Widowed & $46.9 \%(n=15)$ & \\
\hline \multicolumn{3}{|l|}{ Employment Status } \\
\hline Full-time & $56.3 \%(\mathrm{n}=18)$ & \\
\hline Part-time/Unemployed/Student/Retired/Disabled & $43.8 \%(n=14)$ & \\
\hline \multicolumn{3}{|l|}{ Education } \\
\hline High school degree or GED & $40.6 \%(n=13)$ & \\
\hline $\begin{array}{l}\text { Some college or } \\
\text { vocational school }\end{array}$ & $43.8 \%(n=14)$ & \\
\hline 4 year college degree/Master's Degree & $15.6 \%(\mathrm{n}=5)$ & \\
\hline \multicolumn{3}{|l|}{ Current Military Status } \\
\hline Reserve & $32.2 \%(\mathrm{n}=10)$ & \\
\hline Retired & $67.7 \%(\mathrm{n}=21)$ & \\
\hline \multicolumn{3}{|l|}{ Childhood Trauma Questionnaire (CTQ) } \\
\hline Sexual Abuse & $6.56(4.17)$ & \\
\hline Physical Abuse & $8.03(3.75)$ & \\
\hline Emotional Abuse & $8.31(4.55)$ & \\
\hline Physical Neglect & $9.34(8.82)$ & \\
\hline Emotional Neglect & $9.63(4.29)$ & \\
\hline Total Score & $8.06(2.61)$ & \\
\hline
\end{tabular}


Table 2. Primary, secondary and descriptive clinical, neurocognitive and neuroendocrine change scores for Gulf War veterans in overall sample

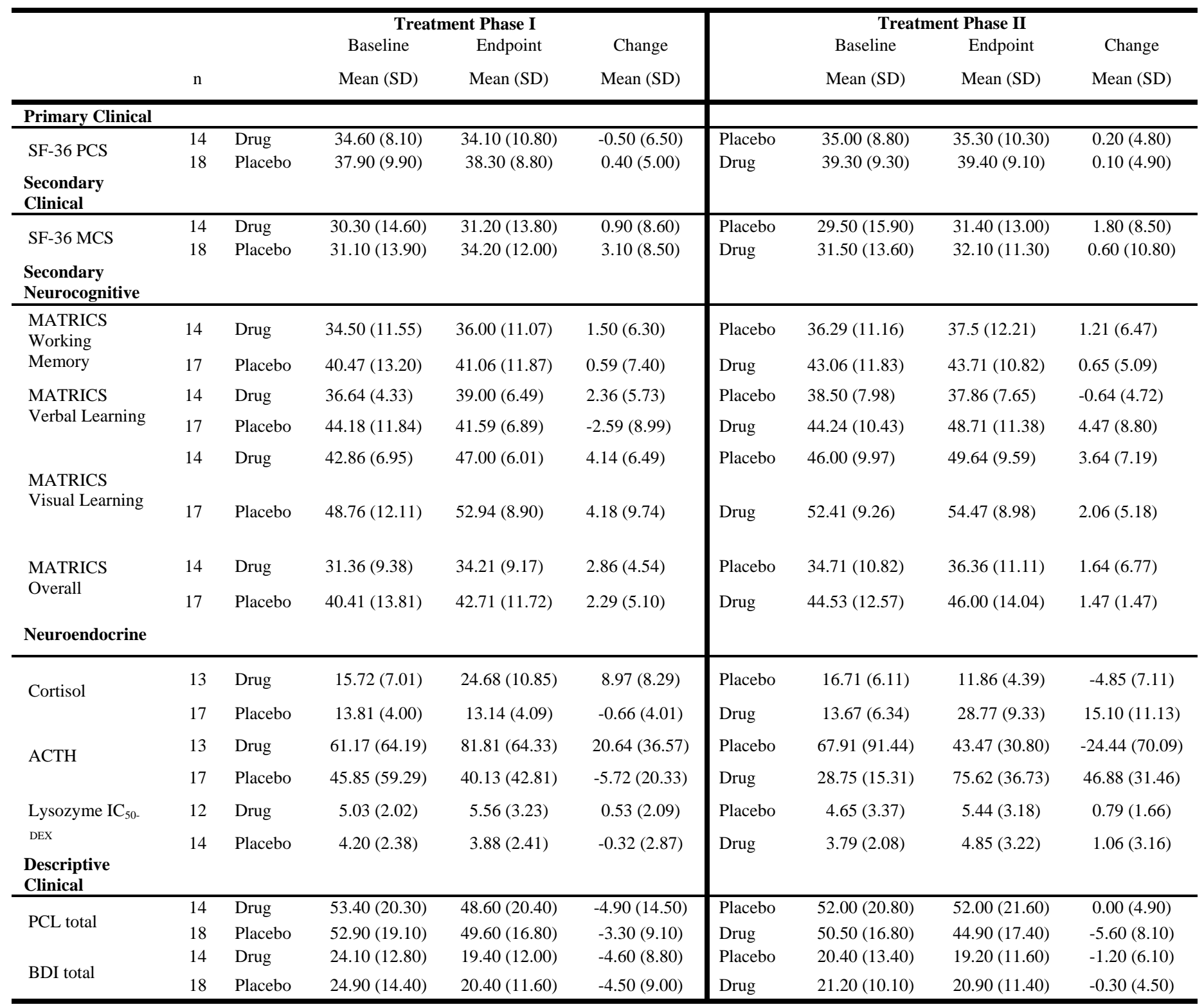


Table 3. Primary, secondary and descriptive clinical, neurocognitive and neuroendocrine outcomes for Gulf War veterans in overall sample

\begin{tabular}{|c|c|c|c|c|c|c|c|c|c|c|}
\hline & \multicolumn{5}{|c|}{ Overall } & \multicolumn{5}{|c|}{ Examination of Treatment Order Effects } \\
\hline & $\mathrm{n}$ & Mean (SD) & $\mathrm{T}$ & df & p-value & Order & Mean (SD) & $\mathrm{t}$ & df & p-value \\
\hline \multicolumn{11}{|l|}{ Primary Clinical } \\
\hline SF-36 PCS & 32 & $-0.46(7.76)$ & -0.34 & 31 & 0.738 & $\begin{array}{l}M(n=14) \\
P(n=18)\end{array}$ & $\begin{array}{l}-0.71(7.83) \\
-0.27(7.93)\end{array}$ & -0.16 & 30 & 0.877 \\
\hline SF-36 MCS & 32 & $-1.89(12.49)$ & -0.81 & 31 & 0.423 & $\begin{array}{l}M(n=14 \\
P(n=18)\end{array}$ & $\begin{array}{l}-0.96(14.15) \\
-2.45(11.42)\end{array}$ & 0.33 & 30 & 0.744 \\
\hline \multicolumn{11}{|l|}{$\begin{array}{l}\text { Secondary } \\
\text { Neurocognitive } \\
\end{array}$} \\
\hline $\begin{array}{l}\text { MATRICS working } \\
\text { memory }\end{array}$ & 31 & $0.16(8.26)$ & 0.11 & 30 & 0.914 & $\begin{array}{l}M(n=14) \\
P(n=17)\end{array}$ & $\begin{array}{l}0.29(9.19) \\
0.06(7.7)\end{array}$ & 0.07 & 29 & 0.941 \\
\hline $\begin{array}{l}\text { MATRICS verbal } \\
\text { learning }\end{array}$ & 31 & $5.23(10.29)$ & 2.83 & 30 & 0.008 & $\begin{array}{l}M(n=14) \\
P(n=17)\end{array}$ & $\begin{array}{c}3(8.36) \\
7.06(11.58)\end{array}$ & -1.10 & 29 & 0.282 \\
\hline $\begin{array}{l}\text { MATRICS visual } \\
\text { learning }\end{array}$ & 31 & $-0.94(11.12)$ & -0.47 & 30 & 0.643 & $\begin{array}{l}M(n=14) \\
P(n=17)\end{array}$ & $\begin{array}{c}0.5(12.11) \\
-2.12(10.46)\end{array}$ & 0.65 & 29 & 0.524 \\
\hline MATRICS overall & 31 & $0.10(6.83)$ & 0.08 & 30 & 0.937 & $\begin{array}{l}M(n=14) \\
P(n=17)\end{array}$ & $\begin{array}{c}1.21(8.71) \\
-0.82(4.63)\end{array}$ & 0.83 & 29 & 0.411 \\
\hline \multicolumn{11}{|l|}{ Neuroendocrine } \\
\hline Cortisol & 30 & $14.92(12.65)$ & 6.46 & 29 & $<0.001$ & $\begin{array}{l}M(n=13) \\
P(n=17)\end{array}$ & $\begin{array}{c}13.82(13) \\
15.76(12.7)\end{array}$ & -0.41 & 28 & 0.683 \\
\hline ACTH & 30 & $49.34(54.40)$ & 4.97 & 29 & $<0.001$ & $\begin{array}{l}M(n=13) \\
P(n=17)\end{array}$ & $\begin{array}{c}45.08(70.02) \\
52.6(40.76)\end{array}$ & -0.37 & 28 & 0.714 \\
\hline Lysozyme $\mathrm{IC}_{50 \text {-DEX }}$ & 29 & $1.21(4.28)$ & 1.53 & 28 & 0.138 & $\begin{array}{l}M(n=12) \\
P(n=17)\end{array}$ & $\begin{array}{c}-0.26(2.18) \\
1.39(4.3)\end{array}$ & -1.20 & 24 & 0.243 \\
\hline \multicolumn{11}{|l|}{ Descriptive Clinical } \\
\hline PCL total & 32 & $-3.38(12.26)$ & -1.56 & 31 & 0.130 & $\begin{array}{l}M(n=14) \\
P(n=18)\end{array}$ & $\begin{array}{l}-4.86(14.93) \\
-2.22(10.03)\end{array}$ & -0.60 & 30 & 0.555 \\
\hline BDI total & 32 & $0.88(9.22)$ & 0.54 & 31 & 0.595 & $\begin{array}{l}M(n=14) \\
P(n=18)\end{array}$ & $\begin{array}{c}-3.43(10.38) \\
4.22(6.75)\end{array}$ & -2.52 & 30 & 0.017 \\
\hline CFQ total & 32 & $1.06(15.46)$ & 0.39 & 31 & 0.700 & $\begin{array}{l}M(n=14) \\
P(n=18)\end{array}$ & $\begin{array}{c}-0.64(13.93) \\
2.39(16.82)\end{array}$ & -0.54 & 30 & 0.590 \\
\hline $\begin{array}{l}\text { MFI-20 general } \\
\text { fatigue (GF) }\end{array}$ & 32 & $0.63(3.37)$ & 1.05 & 31 & 0.302 & $\begin{array}{l}M(n=14) \\
P(n=18)\end{array}$ & $\begin{array}{l}-0.14(4.22) \\
1.22(2.49)\end{array}$ & -1.14 & 30 & 0.262 \\
\hline
\end{tabular}


Table 4. Hierarchical regression of HPA axis biomarkers predicting verbal learning sres.

\begin{tabular}{|c|c|c|c|c|}
\hline Predictor & $\beta$ & $S E \beta$ & $p$-value & $\Delta \mathrm{r} 2$ \\
\hline \multicolumn{5}{|l|}{ Step 1} \\
\hline Treatment Phase & -1.59 & 1.20 & 0.189 & 0.028 \\
\hline Treatment Order & -2.74 & 1.21 & 0.028 & 0.080 \\
\hline Drug Condition & 2.22 & 1.20 & 0.070 & 0.053 \\
\hline Education & 0.86 & 0.81 & 0.294 & 0.017 \\
\hline \multicolumn{5}{|l|}{ Step 2} \\
\hline Verbal Learning Baseline & 0.59 & 0.10 & 0.000 & 0.328 \\
\hline Treatment Phase & -1.15 & 0.93 & 0.222 & 0.014 \\
\hline Treatment Order & -1.41 & 0.96 & 0.149 & 0.020 \\
\hline Drug Condition & 2.52 & 0.93 & 0.009 & 0.069 \\
\hline Education & -0.05 & 0.65 & 0.934 & 0.000 \\
\hline \multicolumn{5}{|l|}{ Step 3} \\
\hline Verbal Learning Baseline & 0.49 & 0.10 & 0.000 & 0.199 \\
\hline Treatment Phase & -1.23 & 0.84 & 0.149 & 0.016 \\
\hline Treatment Order & -1.39 & 0.96 & 0.152 & 0.016 \\
\hline Drug Condition & 2.46 & 0.83 & 0.005 & 0.066 \\
\hline Education & 0.66 & 0.63 & 0.302 & 0.008 \\
\hline Lysozyme $\mathrm{IC}_{50-\mathrm{DEX}}$ & -1.12 & 0.40 & 0.007 & 0.060 \\
\hline DST Cortisol Difference & 0.48 & 0.18 & 0.012 & 0.051 \\
\hline DST ACTH Difference & 0.02 & 0.02 & 0.315 & 0.008 \\
\hline
\end{tabular}


Table 5. Multiple regression testing for cortisol change as a mediator of verbal learning.

\begin{tabular}{|c|c|c|c|c|}
\hline Predictor & $\beta$ & $S E \beta$ & $p$-value & $\Delta \mathrm{r} 2$ \\
\hline \multicolumn{5}{|l|}{ Step 1- outcome: cortisol change } \\
\hline Verbal Learning Baseline & -0.09 & 0.10 & 0.367 & 0.009 \\
\hline Education & 0.17 & 0.57 & 0.765 & 0.001 \\
\hline Treatment Phase & -2.27 & 0.86 & 0.011 & 0.073 \\
\hline Treatment Order & -0.23 & 0.90 & 0.798 & 0.001 \\
\hline Drug Condition (path a) & 4.40 & 0.85 & 0.000 & 0.280 \\
\hline \multicolumn{5}{|c|}{ Step 2 - outcome: endpoint verbal learning } \\
\hline Verbal Learning Baseline & 0.59 & 0.09 & 0.000 & 0.330 \\
\hline Education & 0.18 & 0.50 & 0.714 & 0.001 \\
\hline Treatment Phase & -1.02 & 0.82 & 0.220 & 0.012 \\
\hline Treatment Order & -1.39 & 0.87 & 0.116 & 0.020 \\
\hline Drug Condition (path c') & 2.14 & 0.82 & 0.012 & 0.054 \\
\hline \multicolumn{5}{|c|}{ Step 3 - outcome: endpoint verbal learning } \\
\hline Verbal Learning Baseline & 0.59 & 0.09 & 0.000 & 0.311 \\
\hline Education & 0.27 & 0.55 & 0.622 & 0.002 \\
\hline Treatment Phase & 0.71 & 1.71 & 0.679 & 0.001 \\
\hline Treatment Order & -1.79 & 0.87 & 0.045 & 0.031 \\
\hline Cortisol Baseline & 0.15 & 0.14 & 0.318 & 0.008 \\
\hline Drug Condition (path c) & 1.01 & 0.97 & 0.301 & 0.008 \\
\hline Cortisol Change (path b) & 0.31 & 0.13 & 0.016 & 0.045 \\
\hline
\end{tabular}

Note. For Drug Condition, those who received Mifepristone are coded "1" and Placebo as "-1." For Treatment Phase, Phase 1 is coded as "-1" and Phase 2 as "1." For Treatment Group, Mifepristone first is coded as " 1 " and Placebo first as "- 1 ." 
Figure 1. Participant flow chart.

\section{Enrollment}

Assessed for eligibility $(n=65)$

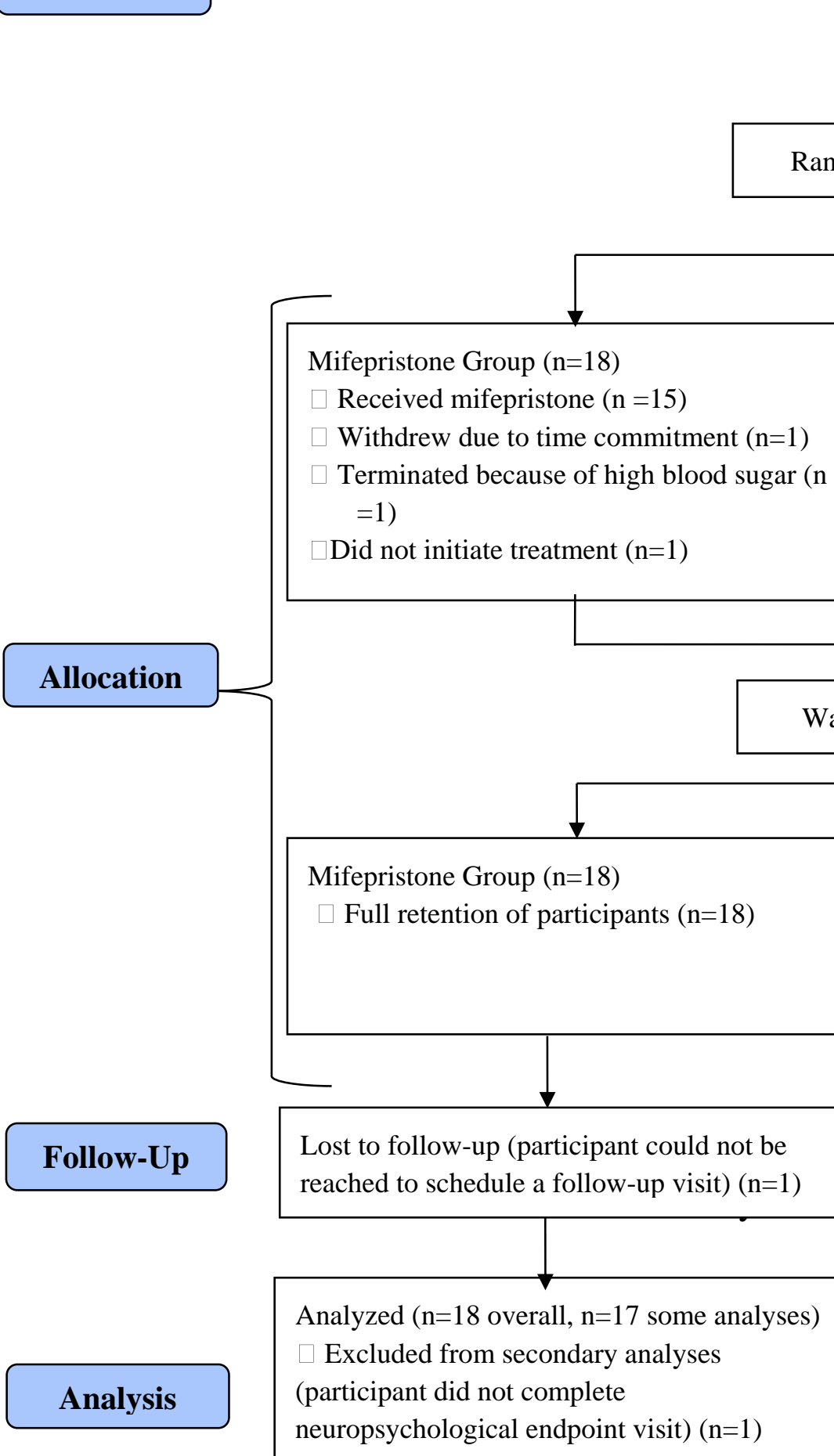

Excluded $(\mathrm{n}=29)$

Not meeting inclusion criteria $(n=14)$

Declined to participate $(\mathrm{n}=2)$

Lost to follow-up $(n=13)$

Randomized $(\mathrm{n}=36)$

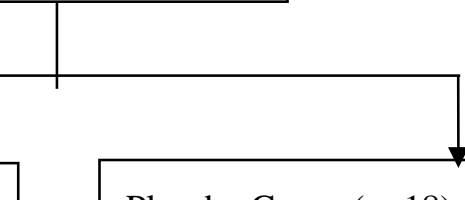

Placebo Group ( $\mathrm{n}=18)$

Full retention of participants $(\mathrm{n}=18)$

Withdrew due to time commitment $(\mathrm{n}=1)$

Terminated because of high blood sugar ( $n$ $=1$

Did not initiate treatment $(\mathrm{n}=1)$

\section{Washout (30 days)}


Figure 2. MATRICS Verbal Learning Score Change.

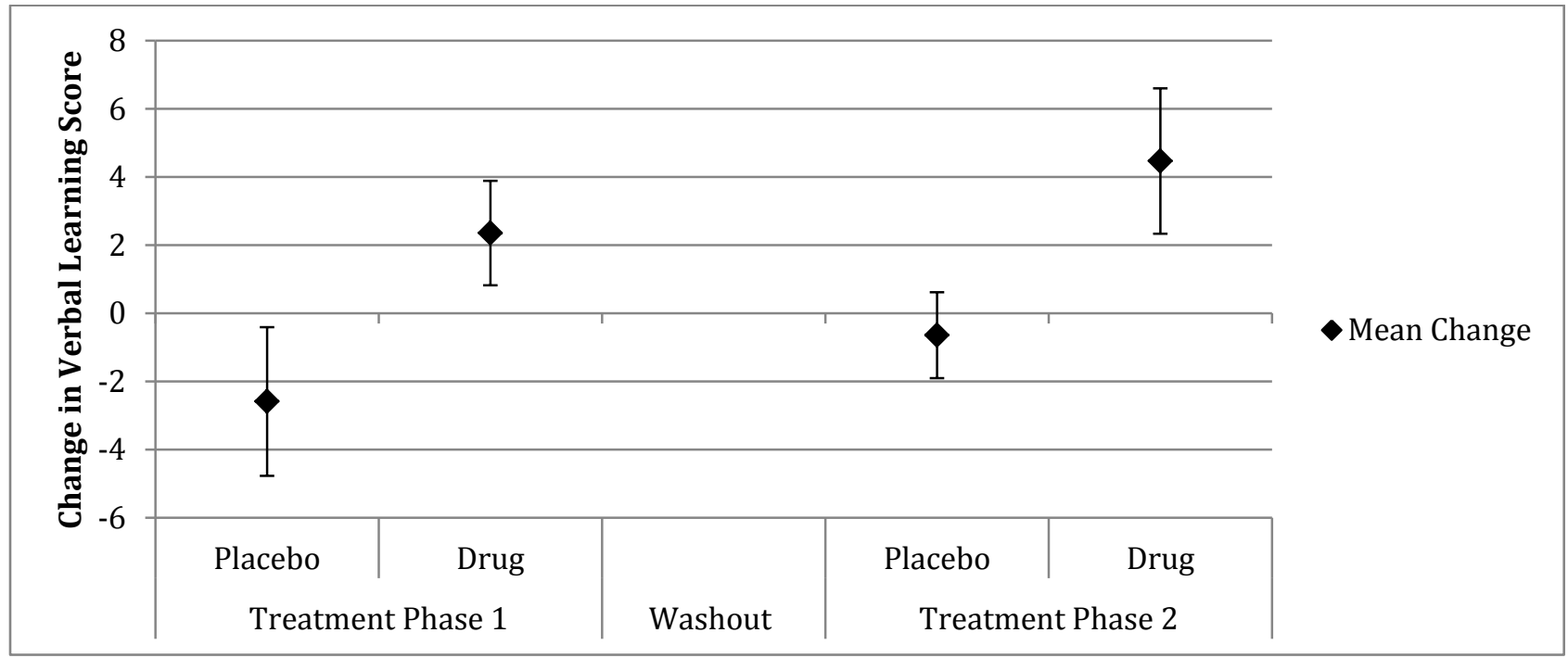

Note. Error bars $= \pm$ standard error of the mean 
Figure 3. Study Cortisol Fluctuations.

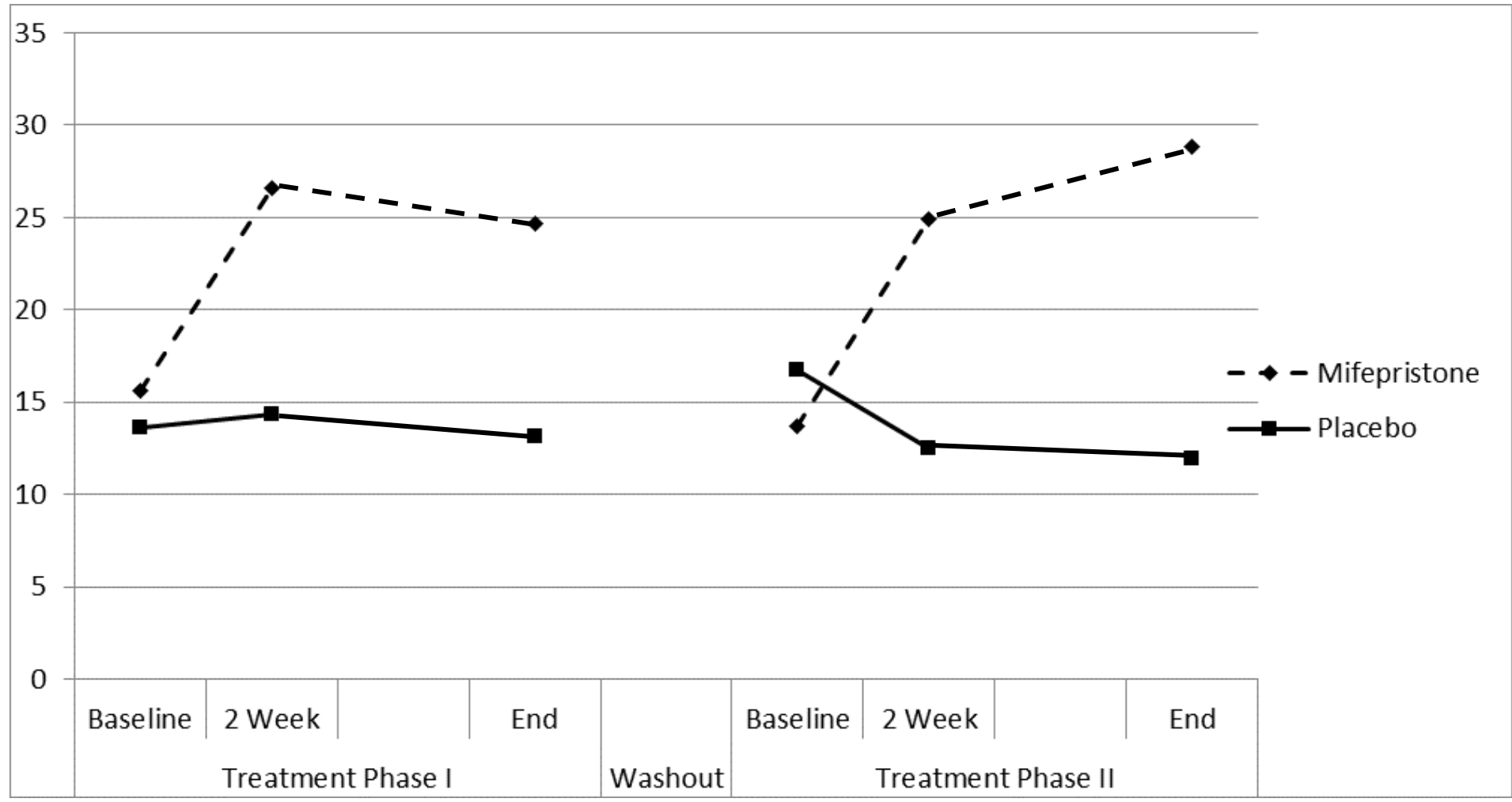


Figure 4. Cortisol mediation of drug on verbal learning.

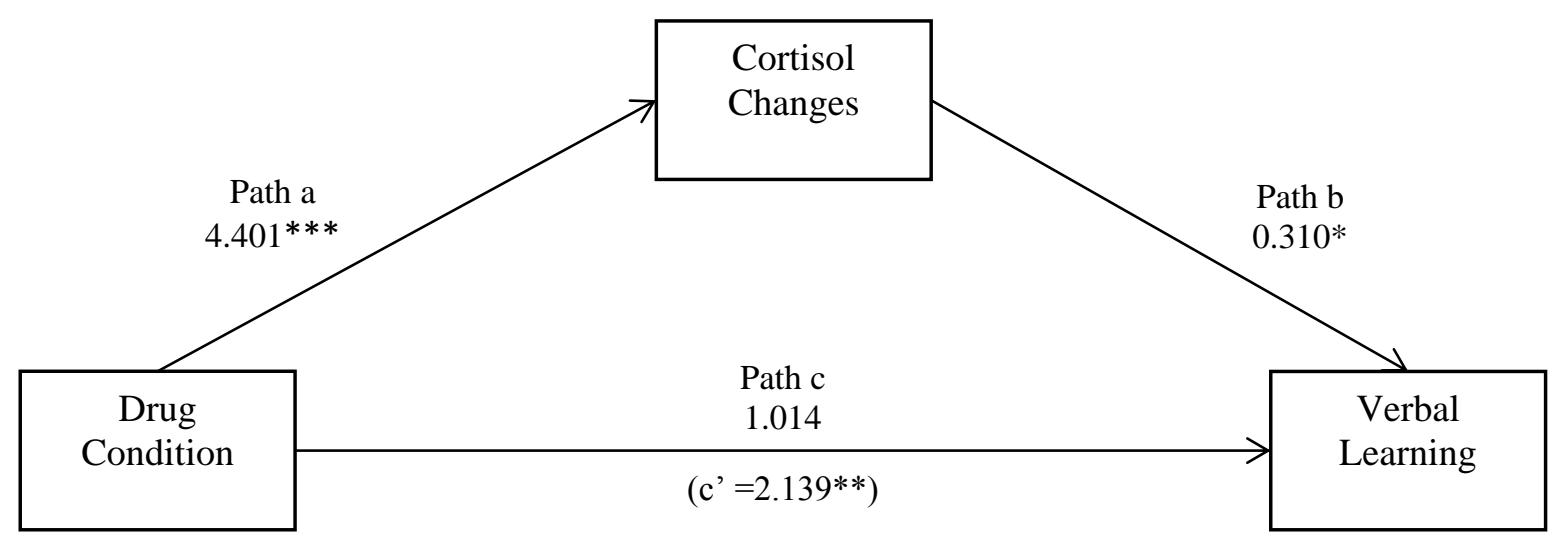

Note. Control variables are omitted from graphical depiction. ${ }^{*} \mathrm{p}<0.05$, $* * \mathrm{p}<0.01,{ }^{*} * \mathrm{p}<0.001$ 